in vivo $33: 1307-1311(2019)$

doi:10.21873/invivo.11604

\title{
Feasibility and Effectiveness of Gastrectomy for Elderly Gastric Cancer Patients
}

\author{
YASUNORI OTOWA, SHUJI OKAMOTO, RYOSUKE FUJINAKA, \\ KEISUKE ARAI, KOICHI MURATA, YASUHIKO MII, KEITARO KAKINOKI, \\ SHIGETERU OKA and DAISUKE KURODA
}

Department of Surgery, Kita-Harima Medical Center, Ono, Japan

\begin{abstract}
Background/Aim: The benefits of gastrectomy for elderly gastric cancer $(G C)$ patients remain unknown. The aim of this study was to evaluate the validity of gastrectomy. Patients and Methods: Patients who had RO or R1 resection and diagnosed as pathological Stage I-III GC were enrolled in this study. Patients were classified according to age: Elderly group ( $\geq 80$ years old), non-Elderly group (70-79 years old), Standard group ( $\leq 69$ years old). Results: As the age raised, the number of comorbidities increased and patients had a worse physical status. Operative procedure and postoperative complications of the Elderly group were similar to that of the non-Elderly group. The overall survival was similar in pathological Stages I and III between the Elderly and non-Elderly groups, while the Stage II Elderly group had shorter overall survival. Also, the Elderly group did not undergo adjuvant chemotherapy compared to other groups. Conclusion: Gastrectomy can be performed safely in elderly patients following gastrectomy, survival of elderly patients was similar to non-elderly patients. Therefore, gastrectomy is an acceptable treatment for elderly patients in good condition.
\end{abstract}

The incidence of Gatric cancer has declined over the past decades (1); however, it is still one of the most common cancers worldwide (2). Gastrectomy is the main treatment for gastric cancer, but it might associate with severe postoperative gastrointestinal symptoms. Previous reports have shown that postoperative morbidity leads to poor prognosis, especially in elderly patients $(3,4)$.

This article is freely accessible online.

Correspondence to: Yasunori Otowa, Department of Surgery, KitaHarima Medical Center, 926-250 Ichiba-cho, Ono city, Hyogo 6751392, Japan. Tel: +81 794888800, Fax: +81 794629931, e-mail: dregg338@gmail.com

Key Words: Elderly, gastric cancer, gastrectomy.
Aging is accompanied by a decline in the function of critical organs $(5,6)$. Postoperative morbidity and mortality increases as the age increases. Moreover, elderly patients often have several comorbidities at the time of diagnosis that sometimes affect survival $(7,8)$. Therefore, it is difficult to predict surgical risk, since physical status varies greatly among elderly individuals.

The rate of gastrectomy in the elderly is increasing (9). Previous articles have shown that gastrectomy can be performed safely in elderly patients as in non-elderly patients $(10,11)$. However, following gastrectomy, pneumonia often develops leading to death of elderly patients (12). Also, elderly patients are likely to develop malnutrition (13). Therefore, it is still unclear whether gastrectomy improves the overall survival of elderly patients. The aim of this study was to evaluate whether gastrectomy is beneficial for elderly gastric cancer patients.

\section{Patients and Methods}

Study design. A single institutional retrospective cohort study was performed at the Kita-Harima Medical Center Hospital from January 2014 to December 2017. All patients who had R0 or R1 resection and diagnosed as pathological Stage I-III were enrolled into this study. Since younger patients tend to have less comorbidities and a better physical status, those under 70 years were considered as standard controls. We defined those over 80 years old as the Elderly group and those between 70-79 years old as the non-Elderly group.

Clinical characteristics, surgical outcomes, pathological findings and follow-up data were extracted from medical records. Physical status was assessed based on the following factors: age, gender, American Society of Anesthesiologists (ASA) score, Charlson comorbidity index (CCI), body mass index (BMI), and modified Glasgow Prognostic score (mGPS). Tumor status was diagnosed according to the Japanese Gastric Cancer Association classification system (14). Operative complications were graded according to the Clavien-Dindo classification and complications higher than grade II were defined as post-operative complications (15). The study design was approved by the ethics review board at Kita-Harima Medical Center and conforms to the provisions of the 1995 Declaration of Helsinki. 
Table I. Patient characteristics.

\begin{tabular}{|c|c|c|c|c|}
\hline Variables & Standard $(\mathrm{n}=78)$ & Elderly group $(\mathrm{n}=39)$ & Non-elderly group $(n=78)$ & $p$-Value \\
\hline Gender (Male/Female) & $54 / 24$ & $28 / 11$ & $63 / 15$ & 0.237 \\
\hline Histology (differentiated/non-differentiated/special) & $39 / 36 / 2$ & $24 / 14 / 1$ & $43 / 33 / 2$ & 0.838 \\
\hline $\mathrm{BMI}$, mean $\pm \mathrm{SD}, \mathrm{kg} / \mathrm{m}^{2} / \mathrm{m}^{2}$ & $22.9 \pm 3.2$ & $22.0 \pm 3.5$ & $22.0 \pm 3.2$ & 0.174 \\
\hline ASA score $(0,1 / 2,3)$ & $71 / 7$ & $23 / 16$ & $63 / 15$ & $<0.001$ \\
\hline WBC, median (range), $\times 10^{2} \mu \mathrm{l}$ & $61.2(32.9-122.1)$ & $60.8(28.5-118.9)$ & $60.0(39.8-125.9)$ & 0.850 \\
\hline $\mathrm{Hb}$, median (range), mg/dl & $13.8(8.0-17.3)$ & $12.4(6.4-15.6)$ & $12.7(7.6-17.9)$ & 0.002 \\
\hline Plt, median (range), $\times 10^{4} \mu l$ & $23.7(13.4-59.6)$ & $20.6(8.5-34.7)$ & $22.7(4.8-38.2)$ & 0.020 \\
\hline Alb, median (range), mg/dl & $4.3(2.5-5.0)$ & $3.7(2.3-4.4)$ & $4.0(1.7-4.9)$ & $<0.001$ \\
\hline $\mathrm{CRP}$, median (range), $\mathrm{mg} / \mathrm{dl}$ & $0.07(0.01-7.26)$ & $0.20(0.01-13.98)$ & $0.11(0.01-21.55)$ & 0.017 \\
\hline $\mathrm{Cr}$, median (range), mg/dl & $0.80(0.51-7.13)$ & $0.77(0.48-6.22)$ & $0.81(0.48-3.52)$ & 0.545 \\
\hline eGFR, median (range), $\mathrm{ml} / \mathrm{min} / 1.73$ & $72.5(7-104)$ & $63(7-106)$ & $67(14-101)$ & 0.002 \\
\hline mGPS $(0 / 1 / 2)$ & $73 / 2 / 3$ & $29 / 3 / 7$ & $69 / 1 / 8$ & 0.024 \\
\hline Pathological T status $(1,2 / 3,4)$ & $45 / 33$ & $20 / 19$ & $42 / 36$ & 0.775 \\
\hline Pathological $\mathrm{N}$ status $(0,1 / 2,3)$ & $55 / 23$ & $23 / 16$ & $57 / 21$ & 0.324 \\
\hline Pathological Stage (I/II/III) & $39 / 16 / / 23$ & $13 / 14 / 12$ & $39 / 17 / 22$ & 0.317 \\
\hline $\mathrm{CCI}(\leq 2 / 3 \leq)$ & $74 / 4$ & $28 / 11$ & $64 / 14$ & 0.003 \\
\hline
\end{tabular}

BMI: Body mass index; ASA: American Society of Anesthesiologist, WBC: white blood cell; Hb: hemoglobin; Plt: platelet; Alb: albumin; CRP: C-reactive protein; Cr: creatinine; eGFR: estimate glomerular filtration rate; mGPS: modified glasgow prognostic score; CCI: Charlson comorbidity index.

Statistical analysis. The difference between two groups was analyzed by using the Fisher's exact test or Chi-square test and Student's T test or Mann-Whitney $U$-test. Cumulative survival rate was calculated by the Kaplan-Meier method, and survival curves were compared using the log-rank test. In all analyses, a $p<0.05$ was accepted as statistically significant. Descriptive statistics were obtained using the SPSS 24.0 for Windows (SPSS Inc., Chicago, IL, USA).

\section{Results}

One hundred ninety-five patients were enrolled into this study. Among them, 78 patients $(40.0 \%)$ were under 70 years old, 78 patients $(40.0 \%)$ were aged between $70-79$ years old, and 39 patients $(20.0 \%)$ were over 80 years old.

The patients' characteristics are listed in Table I. ASA score $\geq 2$ was significantly more frequently observed as the age raised $(p<0.001)$. Also, albumin levels decreased and Creactive protein (CRP) levels increased with age $(p<0.001$ and $p=0.017$, respectively). Moreover, higher mGPS was more frequently observed with increasing age $(p=0.024)$. Estimated glomerular filtration rate (eGFR) decreased with age $(p=0.002)$, despite the absence of difference in creatinine levels. CCI increased with age $(p=0.003)$. There was no significant difference in other factors.

The surgical outcomes are listed in Table II. The operation time did not differ between groups $(p=0.159)$. Blood loss was more often observed at older ages $(p=0.021)$. There were no differences in laparoscopic surgery rate, operative procedure, lymph node dissection, and $\mathrm{R} 0$ resection rate. Moreover, there were no differences in leakage, pancreatic fistula, and respiratory complications. The Elderly group had a tendency to have a longer length of hospital stay than other groups; however, the difference was not significant.

Overall survival (OS) and Cancer specific survival (CSS) of each pathological Stage are shown in Figures 1 and 2. The standard group had the longest overall survival in either Stage. For the OS of pathological Stage I, the Elderly group had the worst survival rate compared to other groups. However, the survival rate between Elderly group and nonElderly group was not significantly different $(p=0.237)$. Moreover, none of the patients died of cancer in pathological Stage I in either group. Regarding OS in pathological Stage II, the Elderly group had a lower survival rate compared to standard and non-Elderly groups $(p=0.113$ and $p=0.038$, respectively). On the other hand, the OS was similar between standard and non-Elderly groups. Similar result was observed for CSS in pathological Stage II. Regarding the OS and CSS of pathological Stage III, survival was similar between Elderly and non-Elderly groups. Among patients who were diagnosed as pathological Stage II or III, the patients who had adjuvant chemotherapy decreased with age $(p<0.001$, Table III). A similar trend was observed in pathological Stage II and III.

\section{Discussion}

Our results showed that gastrectomy can be performed safely in elderly without increasing the postoperative complications. Also, the survival rate in pathological I and III was similar between Elderly and non-Elderly groups. There are previous studies that have compared elderly and non-elderly; however, these studies classified the patients 
Table II. Postoperative outcomes

\begin{tabular}{|c|c|c|c|c|}
\hline Variables & Standard $(n=78)$ & Elderly group $(n=39)$ & Non-elderly group $(\mathrm{n}=78)$ & $p$-Value \\
\hline Operation time, median (range), min & $343(211-876)$ & $309(146-481)$ & $338(151-727)$ & 0.159 \\
\hline Blood loss, & $150(0-10583)$ & $300(0-1025)$ & $167.5(0-1900)$ & 0.021 \\
\hline Laparoscopic surgery (\%) & $45(57.7)$ & $16(41.0)$ & $48(61.5)$ & 0.105 \\
\hline Total gastrectomy $(\%)$ & $32(41.0)$ & $14(35.9)$ & $32(41.0)$ & 0.845 \\
\hline Lymph node dissection (D1+/D2) & $47 / 31$ & $28 / 11$ & $48 / 30$ & 0.487 \\
\hline R0 resection $(\%)$ & $78(100)$ & $77(98.7)$ & $38(97.4)$ & 0.678 \\
\hline All complications $(\%)$ & $17(21.8)$ & $12(30.8)$ & $31(39.7)$ & 0.055 \\
\hline Leakage $(\%)$ & $5(6.4)$ & $2(5.1)$ & $6(7.7)$ & 0.935 \\
\hline Pancreatic fistula (\%) & $8(10.3)$ & $3(7.7)$ & $6(7.7)$ & 0.850 \\
\hline Respiratory complication (\%) & $2(2.6)$ & $3(7.7)$ & $3(3.8)$ & 0.464 \\
\hline Other complications & $7(9.0)$ & $6(15.4)$ & $19(24.4)$ & 0.035 \\
\hline Length of hospital stay & $15(8-102)$ & $18(8-87)$ & $16(8-124)$ & 0.185 \\
\hline
\end{tabular}

Table III. Numbers of patients who had adjuvant chemotherapy in pathological Stage II and III.

\begin{tabular}{|c|c|c|c|c|}
\hline & Standard $(\mathrm{n}=39)$ & Elderly group $(\mathrm{n}=26)$ & Non-elderly group $(n=39)$ & $p$-Value \\
\hline Adjuvant chemotherapy (\%) & $30(76.9)$ & $5(8.9 \%)$ & $21(37.5)$ & $<0.001$ \\
\hline Pathological Stage II (\%) & $9(56.3)$ & $3(21.4)$ & $8(47.1)$ & 0.167 \\
\hline Pathological Stage III (\%) & $21(91.3)$ & $2(5.6)$ & $13(59.1)$ & $<0.001$ \\
\hline
\end{tabular}

only into two groups $(10,11,16)$. Since, younger patients have less comorbidities and longer expectancy than elderly, fine classification of patients is needed to compare the surgical short- and long-term outcomes, as in our study.

The JCOG0703 study in which the majority of the patients were pathological Stage I, has shown that no patients had recurrent disease and the 5-year OS and RFS were both $98.2 \%$ (17). Although, in that study the median age was 59 years old, a similar result was obtained in the current study: no patients had recurrent disease in pathological Stage I. Also, there was no difference in OS, RFS, and CSS between Elderly and non-Elderly groups in pathological Stage III. This might be due to reduced effectiveness of S-1 in pathological Stage III, in contrast to a clear survival benefit in pathological Stage II $(18,19)$. Also, in that study, the benefit of S-1 was more significant in younger age than in older age. Therefore, the benefit of S-1 may be limited to patients over 80 years old in pathological Stage III.

Despite the fact that survival was similar between Elderly and non-Elderly groups in pathological stage I and III, the Elderly group had worse survival in pathological Stage II than the non-Elderly group. One possible reason might be the low rate of adjuvant chemotherapy. Patients tend to refuse adjuvant chemotherapy with increasing age. Also, we tend not to recommend adjuvant chemotherapy, since the effectiveness of performing adjuvant chemotherapy in elderly patients is unknown and aging itself is a risk factor for poor compliance with adjuvant chemotherapy (20). Therefore, a randomized control study is being carried out by the Japan Clinical Oncology Group to clarify whether adjuvant chemotherapy contributes to improvement of RFS in patients with pathological Stage II/III gastric cancer (21).

There are several limitations to this study. First, this is a retrospective cohort study conducted in a single institution and the sample size was small. Also, since our institution was founded in October 2013, the observation time was quite short which might have contributed to an overestimation of our results. Second, the patients were classified according to the pathological Stage not the clinical stage. Third, the survival of elderly was compared with that of non-elderly patients, since no data were available for the elderly patients not having gastrectomy. However, Endo et al. have shown that gastrectomy improved survival compared to best supportive care for patients above 85 years old (22). Last, there was a tendency to operate elderly patients in good condition.

In conclusion, gastrectomy in elderly patients over 80 years old can be performed safely and survival rate was similar to those of 70-79 years old. Therefore, performing gastrectomy is beneficial for elderly patients in good conditions. 

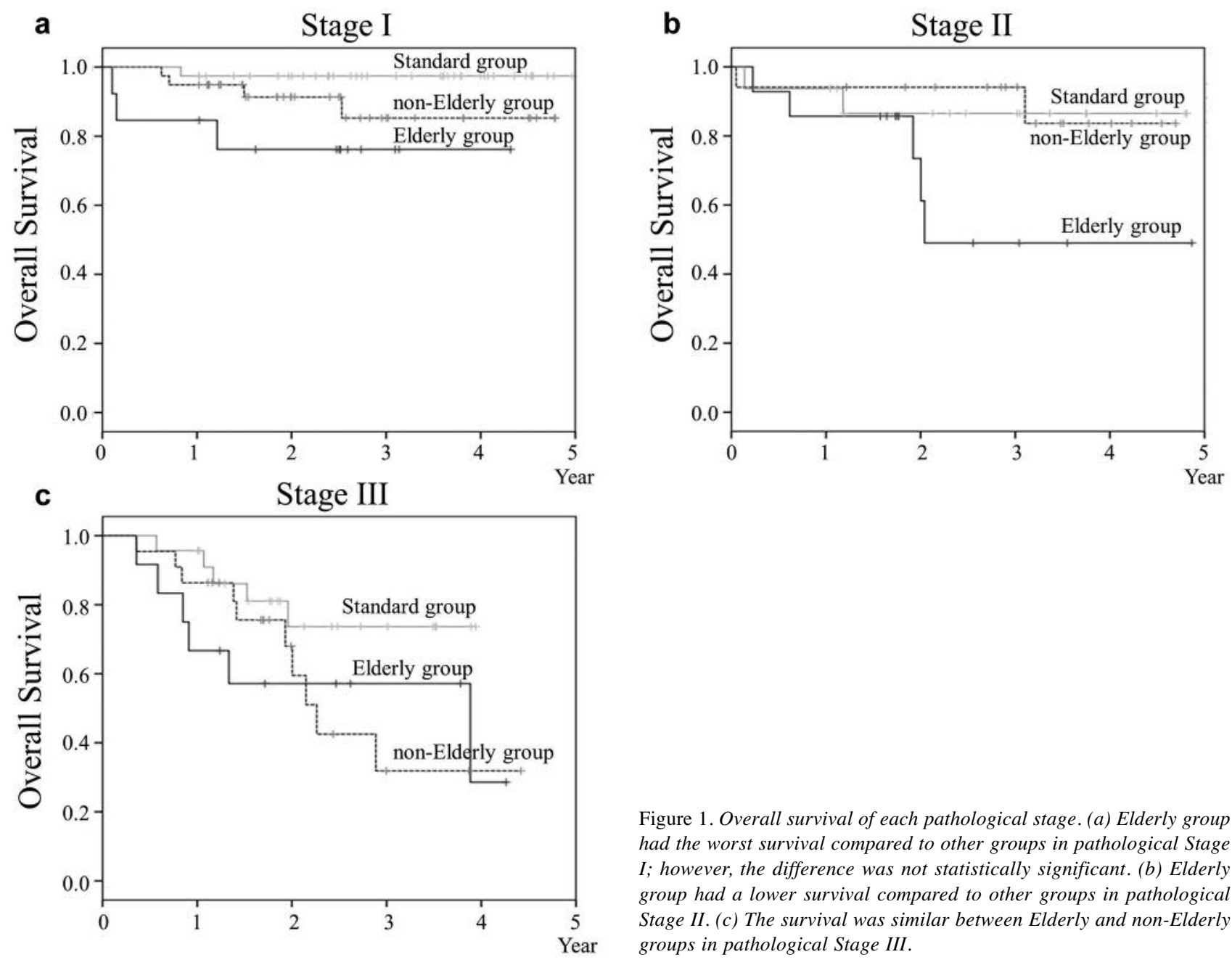

Figure 1. Overall survival of each pathological stage. (a) Elderly group had the worst survival compared to other groups in pathological Stage I; however, the difference was not statistically significant. (b) Elderly group had a lower survival compared to other groups in pathological Stage II. (c) The survival was similar between Elderly and non-Elderly groups in pathological Stage III.
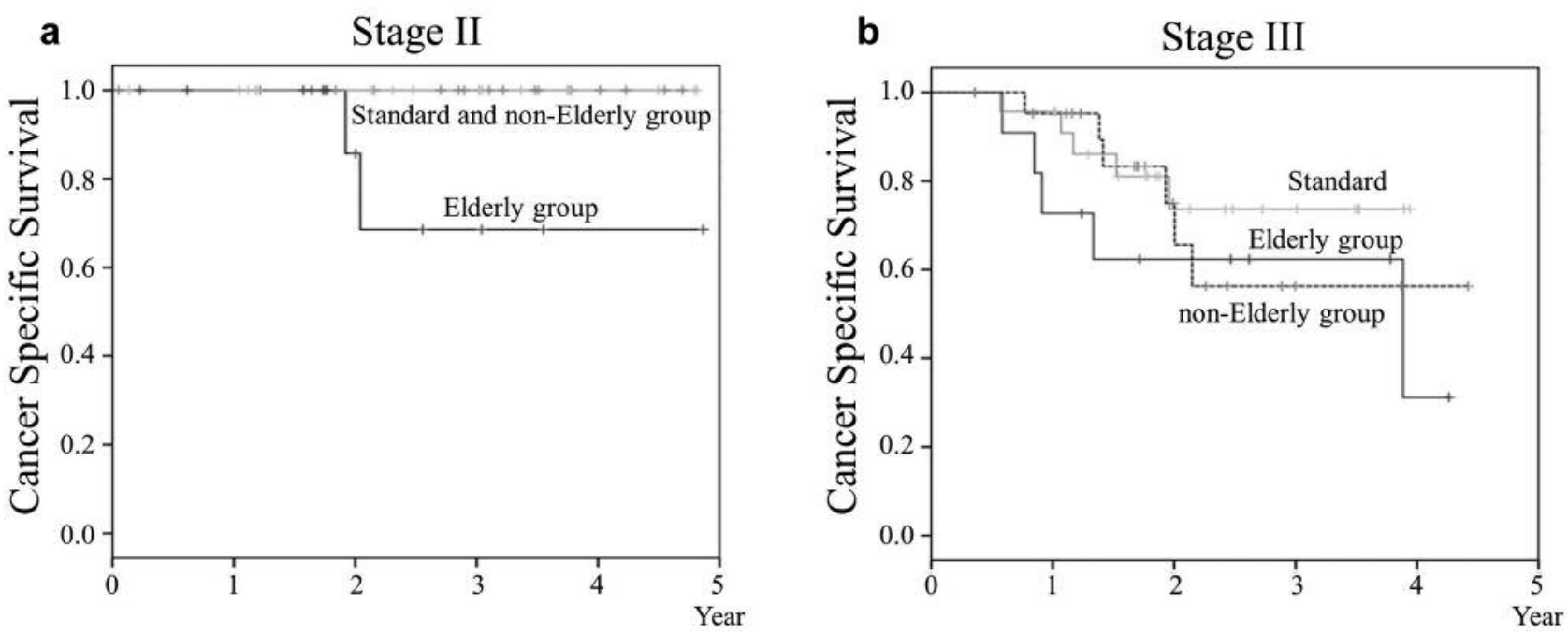

Figure 2. Cancer-specific survival of each pathological stage. (a) The Elderly group had a lower survival compared to other groups in pathological Stage II. (b) The survival was similar between Elderly and non-Elderly groups in pathological Stage III. 


\section{Conflicts of Interest}

The Authors have no conflicts of interest to declare.

\section{Authors' Contributions}

YO and KM conceived the study. SO, RF, and KA collected the data. YO, YM, and KK performed the data analysis. YO wrote the manuscript and SO and DK revised the manuscript. All Authors performed the operation. All Authors approved the final version of the article.

\section{References}

1 Zhu AL and Sonnenberg A: Is gastric cancer again rising? J Clin Gastroenterol 46(9): 804-806, 2012. PMID: 22914346. DOI: 10.1097/MCG.0b013e3182604254

2 Jemal A, Bray F, Center MM, Ferlay J, Ward E and Forman D: Global cancer statistics. CA Cancer J Clin 61(2): 69-90, 2011 PMID: 21296855. DOI: 10.3322/caac.20107

3 Takeuchi D, Koide N, Suzuki A, Ishizone S, Shimizu F, Tsuchiya $\mathrm{T}$, Kumeda S and Miyagawa S: Postoperative complications in elderly patients with gastric cancer. J Surg Res 198(2): 317-326, 2015. PMID: 26033612. DOI: 10.1016/j.jss.2015.03.095

4 Suzuki S, Kanaji S, Matsuda Y, Yamamoto M, Hasegawa H, Yamashita K, Oshikiri T, Matsuda T, Sumi Y, Nakamura T and Kakeji Y: Long-term impact of postoperative pneumonia after curative gastrectomy for elderly gastric cancer patients. Ann Gatroenterol Surg 2(6): 72-78, 2017. PMID: 29863154. DOI: 10.1002/ags3.12037

5 Sawhney R, Sehl M and Naeim A: Physiologic aspects of aging: impact on cancer management and decision making, part I. Cancer J 11(6): 449-460, 2005. PMID: 16393479.

6 Sehl M, Sawhney R and Naeim A: Physiologic aspects of aging: impact on cancer management and decision making, part II. Cancer J 11(6): 461-473, 2005. PMID: 16393480.

7 Yancik R and Ries LA: Cancer in older persons. Magnitude of the problem - how do we apply what we know? Cancer 74(7 Suppl): 1995-2003, 1994. PMID: 8087762.

8 Yancik R, Wesley MN, Ries LA, Havlik RJ, Long S, Edwards BK and Yates JW: Comorbidity and age as predictors of risk for early mortality of male and female colon carcinoma patients: a population-based study. Cancer 82(11): 2123-2134, 1998. PMID: 9610691.

9 Cancer Information Service: Cancer statistics in Japan. Available from: http://ganjoho.jp/en/professional/statistics/brochure/ index. html

10 Kiyokawa T, Hiki N, Nunobe S, Honda M, Ohashi M, Sano T and Yamaguchi T: Feasibility of gastrectomy with standard lymphadenectomy for patients over 85 years old with gastric cancer. Ann Surg Oncol 22(12): 3962-3969, 2015. PMID: 25805234. DOI: $10.1245 / \mathrm{s} 10434-015-4489-0$

11 Wang JF, Zhang SZ, Zhang NY, Wu ZY, Feng JY, Ying LP and Zhang JJ: Laparoscopic gastrectomy versus open gastrectomy for elderly patients with gastric cancer: a systematic review and meta-analysis. World J Surg Oncol 14: 90, 2016. PMID: 27030355. DOI: $10.1186 / \mathrm{s} 12957-016-0859-8$

12 Prina E, Ranzani OT and Torres A: Community-acquired pneumonia. Lancet 386(9998): 1097-1108, 2015. PMID: 2627 7247. DOI: 10.1016/S0140-6736(15)60733-4
13 Ahmed $\mathrm{T}$ and Haboubi $\mathrm{N}$ : Assessment and management of nutrition in older people and its importance to health. Clin Interv Aging 5: 207-216, 2010. PMID: 20711440.

14 Japanese Gastric Cancer Association: Japanese classification of gastric carcinoma: 3rd English edition. Gastric Cancer 14(2): 101-112, 2011. PMID: 21573743. DOI: 10.1007/s10120-0110041-5

15 Dindo D, Demartines N and Clavien PA: Classification of surgical complications: a new proposal with evaluation in a cohort of 6336 patients and results of a survey. Ann Surg 240(2): 205-213, 2004. PMID: 15273542.

16 Hikage M, Tokunaga M, Makuuchi R, Irino T, Tanizawa Y, Bando E, Kawamura T and Terashima M: Surgical outcomes after gastrectomy in very elderly patients with gastric cancer. Surg Today 48(8): 773-782, 2018. PMID: 29536199. DOI: $10.1007 / \mathrm{s} 00595-018-1651-\mathrm{x}$

17 Hiki N, Katai H, Mizusawa J, Nakamura K, Nakamori M, Yoshikawa T, Kojima K, Imamoto H, Ninomiya M, Kitano S, Terashima M and Stomach Cancer Study Group of Japan Clinical Oncology Group: Long-term outcomes of laparoscopyassisted distal gastrectomy with suprapancreatic nodal dissection for clinical stage I gastric cancer: a multicenter phase II trial (JCOG0703). Gastric Cancer 21(1): 155-161, 2018. PMID: 28093654. DOI: 10.1007/s10120-016-0687-0

18 Sakuramoto S, Sasako M, Yamaguchi T, Kinoshita T, Fujii M, Nashimoto A, Furukawa H, Nakajima T, Ohashi Y, Imamura H, Higashino M, Yamamura Y, Kurita A, Arai K and ACTS-GC Group: Adjuvant chemotherapy for gastric cancer with $\mathrm{S}-1$, an oral fluoropyrimidine. N Engl J Med 357(18): 1810-1820, 2007. PMID: 17978289. DOI: 10.1056/NEJMoa072252

19 Sasako M, Sakuramoto S, Katai H, Kinoshita T, Furukawa H, Yamaguchi T, Nashimoto A, Fujii M, Nakajima T and Ohashi Y: Five-year outcomes of a randomized phase III trial comparing adjuvant chemotherapy with $\mathrm{S}-1$ versus surgery alone in stage II or III gastric cancer. J Clin Oncol 29(33): 4387-4393, 2011. PMID: 22010012. DOI: 10.1200/JCO.2011.36.5908

20 Yamashita K, Kurokawa Y, Yamamoto K, Hirota M, Kawabata R, Mikami J, Masuzawa T, Takiguchi S, Mori M and Doki Y: Risk factors for poor compliance with adjuvant s-1 chemotherapy for gastric cancer: A multicenter retrospective study. Ann Surg Oncol 24(9): 2639-2645, 2017. PMID: 286081 66. DOI: $10.1245 / \mathrm{s} 10434-017-5923-2$

21 Mizutani T, Yamaguchi K, Mizusawa J, Ito S, Nishida Y, Yabusaki H, Boku N, Sano T, Yoshida K, Sasako M, Yoshikawa T, Terashima $M$ and Stomach Cancer Study Group/Japan Clinical Oncology Group: A phase III trial to confirm modified S-1 adjuvant chemotherapy for pathological stage II/III vulnerable elderly gastric cancer patients who underwent gastric resection (JCOG1507, BIRDIE). Jpn J Clin Oncol 48(12): 11011104, 2018. PMID: 30346560. DOI: 10.1093/jjco/hyy 152

22 Endo S, Shimizu Y, Ikenaga M, Ohta K and Yamada T: Survival benefit of gastrectomy for gastric cancer in patients $\geq 85$ years old: A retrospective propensity score-matched analysis. Surgery 161(4): 984-994, 2017. PMID: 27894711. DOI: 10.1016/j.surg. 2016.10 .012

Received March 20, 2019

Revised April 23, 2019 Accepted April 24, 2019 